\title{
Exploring the Potential of Flunarizine for Cisplatin-Induced Painful Uremic Neuropathy in Rats
}

\author{
Arunachalam Muthuraman ${ }^{1,2}$, Sumeet Kumar Singla ${ }^{2}$, Anil Peters ${ }^{2}$ \\ ${ }^{1}$ Department of Pharmaceutical Sciences \& Drug Research, Punjabi University, Patiala, Punjab; \\ ${ }^{2}$ Rayat Institute of Pharmacy, Ropar, Punjab, India
}

Purpose: The present study was designed to explore the potential of flunarizine for cisplatin induced painful uremic neuropathy in rats.

Methods: Cisplatin ( $2 \mathrm{mg} / \mathrm{kg}$; i.p., for 5 consecutive days) was administered and renal uremic markers i.e., serum creatinine were estimated on days 4 and 25. Behavioral changes were assessed in terms of thermal hyperalgesia (hot plate, plantar, tail immersion, and tail flick tests at different time intervals). Biochemical analysis of total calcium, superoxide anion, DNA, and transketolase, and myeloperoxidase activity in tissue samples was also performed. Furthermore, flunarizine (100, 200, and $300 \mu \mathrm{M} / \mathrm{kg}$; p.o., for 21 consecutive days) was administered to evaluate its potency on uremic neuropathy, and the results were compared with those for the carbamazepine-treated $(30 \mathrm{mg} / \mathrm{kg}$; p.o., for 21 consecutive days) groups.

Results: Flunarizine attenuated the cisplatin-induced uremic neuropathy, and the degree of behavioral and biochemical changes in serum and tissue samples in a dose dependent manner. The medium and high doses of flunarizine were shown to produce a significant effect on cisplatin induced painful uremic neuropathy.

Conclusions: Our results indicate the potential of flunarizine for anti-oxidative, anti-inflammatory, and neuroprotective actions. Therefore, it may have use as a novel therapeutic agent for the management of painful uremic neuropathy.

Keywords: Hyperalgesia; Peroxidase; Neurotoxins; Transketolase; Uremia

\section{INTRODUCTION}

Uremic neuropathy can be defined as an "Abnormal unpleasant pain sensation along with central-peripheral axonal damage, nerve conduction velocity, and demyelination of the nervous system caused by accumulation of uremic toxin in the circulatory as well as neuronal system". The development of potential uremic neuropathy, i.e., "dying-back neuropathy" and/or "central-peripheral axonopathy" and demyelination is caused by uremic toxins such as parathyroid hormone, $\beta 2$-microglobulin, indoxyl sulfate, potassium, inorganic phosphate, and hydrogen ion [1]. The kidney plays an important role in the elimination of numerous organic anions and cations, including uremic toxins, from the blood into the urine. Clinically, hemodialysis and kidney transplantation can contribute to the development of neurological complications, and observed mortality in patients with uremia [2]. Uremic conditions frequently develop with renal failure and lead to alterations of the central-peripheral nervous system as well as the muscular system. The uremia-induced neuropathic pain progresses over months and has been estimated to be present in 60 to $100 \%$ of patients on dialysis [1].

Cisplatin (cis-diamminedichloroplatinum II) is a divalent platinum-based chemotherapeutic agent used in the management of various types of cancers of vital organs such as the testis, ovary, bladder, lung, and cervical region [3]. The therapeutic effect of cisplatin is dose-dependent. However, clinically, a complete beneficial effect is limited because of the potential for nephrotoxic and neurotoxic effects [4]. The nephrotoxic effect
Corresponding author: Arunachalam Muthuraman

Department of Pharmaceutical Sciences \& Drug Research, Punjabi University, Patiala - 147002, Punjab, India

Tel: +91-998-804-0886 / Fax: +91-410-706-2550

E-mail: arunachalammu@gmail.com

Submitted: September 16, 2011 / Accepted after revision: September 27, 2011
This is an Open Access article distributed under the terms of the Creative Commons Attribution Non-Commercial License (http://creativecommons.org/licenses/by-nc/3.0/) which permits unrestricted non-commercial use, distribution, and reproduction in any medium, provided the original work is properly cited. 
of cisplatin is cumulative and dose-dependent, and often requires dose reduction or withdrawal. It is known that cisplatin treatment damages the proximal tubules of the kidney by different mechanisms, including oxidative stress, inflammation, DNA damage, and apoptosis [5]. Additionally, it has been reported that indoxyl sulfate (a representative of uremic toxin) is involved in the progression of cisplatin-induced renal failure and neurotoxicity [6]. Uremic neuropathy symptoms are insidious in onset and consist of a tingling and prickling sensation in the legs. Paresthesias are most common and usually the earliest symptom. Hyperalgesia is a common symptom of painful uremic neuropathy [7].

Clinically, flunarizine (a T-type calcium channel antagonist) has been widely used for treatment of vertigo, migraine, epilepsy, tinnitus, and liver dysfunction $[8,9]$. Many studies revealed that direct inhibition of oxidative stress by flunarizine may be the critical mechanism in the protection of cisplatin-induced renal toxicity [10]. Moreover, it has also been reported to exert the beneficial effects on cisplatin induced neurotoxicity [11]. The present study was the first attempt to explore the potential of flunarizine for cisplatin-induced painful uremic neuropathy in rats. Various drugs are used in the management of neuropathic pain, but few medications are approved by the Food and Drug Administration for the management of neuropathic pain. One approved drug is carbamazepine, which was approved for the treatment of trigeminal neuralgia on the basis of clinical trials [12]. Carbamazepine is an anti-convulsant and mood-stabilizing agent. It has been used for the treatment of epilepsy, bipolar disorder as well as trigeminal neuralgia. It is also used for a variety of indications such as attention deficit hyperactivity disorder, schizophrenia, phantom limb syndrome, complex regional pain syndrome, paroxysmal extreme pain disorder, neuromyotonia, intermittent explosive disorder, borderline personality disorder and post-traumatic stress disorder [13]. Carbamazepine was reported to treat platinum induced neuropathic pain in human and in rat [14]. Therefore, it was used as a positive control in the present study. The purpose of this study is to investigate the potential effects of flunarizine on cisplatin induced painful uremic neuropathy in rat.

\section{MATERIALS AND METHODS}

\section{Animals}

Wistar rats of either sex weighing between 180 and $200 \mathrm{~g}$ were used. Animals were procured from Punjab Agriculture Univer- sity, Department of Animal Sciences, Ludhiana. They were fed a standard laboratory diet and housed at environmental temperature and humidity. A 12-hour natural light and dark cycle was maintained throughout the experimental protocol. The animals had free access to standard laboratory chow and water ad libitum. The experimental protocol was duly approved by the Institutional Animal Ethics Committee and care of the animals was carried out as per the guidelines of Committee for the Purpose of Control and Supervision of Experiments on Animals (CPCSEA), Ministry of Environment and Forest, Government of India (Reg No:- 874/ac/05/CPCSEA).

\section{Drugs and Chemicals}

Chemicals such as Folin-Ciocalteu's Phenol reagent (Merck Limited, Mumbai, India), bovine serum albumin (Sisco Research Laboratories Pvt. Ltd., Mumbai, India), nitroblue tetrazolium (NBT), deoxyribonucleic acid, and phloroglucinol (SD Fine Chemicals, Mumbai, India) were procured for the present study. Flunarizine, cisplatin, and carbamazepine were gifts from Sun Pharma LTD, Mumbai, India and Ranbaxy Pharmaceuticals, Mumbai, Inidia.

\section{Induction of Uremic Neuropathy}

Cisplatin ( $2 \mathrm{mg} / \mathrm{kg}$ of body weight) was administered intraperitoneally for 5 consecutive days (days 0 to 4 ) to induce uremia in rats [15]. The development of neuropathic pain was assessed from the degree of central and peripheral thermal hyperalgesia as assessed by various methods, i.e., hot plate, plantar, tail immersion, and tail flick tests.

\section{Experimental Protocol}

The Wistar rats were randomly divided into nine groups $(\mathrm{n}=6$ in each group). The groups were as follows.

Group I (Normal control group): Rats were not subjected to any drug or vehicle administration and were kept for 19 days.

Group II (Cisplatin control group): Rats were administered cisplatin ( $2 \mathrm{mg} / \mathrm{kg}$; i.p. for 5 consecutive days) for induction of painful uremic neuropathy.

Group III (Vehicle in cisplatin treated group): Rats were administered to normal saline ( $5 \mathrm{~mL} / \mathrm{kg}$ of $0.9 \% \mathrm{w} / \mathrm{v}$ of sodium chloride, p.o.) for 21 consecutive days (from 4 to 25 ).

Group IV (Flunarizine per se): Rats were administered flunarizine (300 $\mu \mathrm{M} / \mathrm{kg}$; p.o.) for 21 consecutive days (from 4 to 25 ).

Group V (Carbamazepine per se): Rats were administered carbamazepine (30 mg/kg; p.o.) for 21 consecutive days (from 4 
to 25$)$.

Groups VI-VIII (Flunarizine in cisplatin treated group): Rats were administered flunarizine (100, 200, and $300 \mu \mathrm{M} / \mathrm{kg}$; p.o.) for 21 consecutive days (from 4 to 25 ).

Groups IX (Carbamazepine in cisplatin treated group): Rats were administered carbamazepine (30 mg/kg; p.o.) for 21 consecutive days (from 4 to 25 ).

The behavioral tests were performed at different time intervals, i.e., days $0,4,11,18$, and 25 . Blood samples were collected on days 4 and 25 for the estimation of creatinine. On day 25, all of the animals were killed and tissue samples of the sciatic nerve were collected for biochemical analysis.

\section{Behavioral Assessment Hot plate test}

The thermal nociceptive threshold, an index of thermal hyperalgesia, was assessed by the hot plate test as described by Borta and Schwarting [16]. An Eddy's hot plate (RSCO Scientific Equipments, Mumbai, India) was pre-heated and maintained at a temperature of $52.5 \pm 0.5^{\circ} \mathrm{C}$. Rats were placed on the hot plate and the nociceptive threshold was assessed with respect to hind paw licking. Response was recorded in seconds. A cutoff time of 20 seconds was maintained.

\section{Plantar test}

Sensitivity of the right hind paw to radiant heat was measured under a radiant heat lamp source as described by Hargreaves et al. [17]. The intensity of the radiant heat stimulus was maintained at $25 \pm 0.1^{\circ} \mathrm{C}$. Response of paw withdrawal latency was noted in seconds. A cutoff time of 15 seconds was maintained.

\section{Tail heat hyperalgesia test}

Spinal thermal sensitivity was assessed by the tail immersion test as described by Necker and Hellon [18]. Tail heat-hyperalgesia was noted with the immersion of the terminal part of the tail $(1 \mathrm{~cm})$ in water maintained at a temperature of $52.5 \pm 0.5^{\circ} \mathrm{C}$. The duration of the tail withdrawal reflex was recorded, as a response of spinal heat sensation and a cutoff time of 15 seconds was maintained.

\section{Tail flick test}

Spinal thermal sensitivity was assessed by the tail flick test as described by D'Amour and Smith [19]. The temperature of the heating element (Nichrome wire) of an analgesimeter (Adarsh Scientific Industries, Ambala Cantt., India) was maintained at
$52 \pm 0.5^{\circ} \mathrm{C}$. The tail of the rat was placed on the analgesimeter at a uniform distance from the Nichrome wire. The tail flick response was noted. A cutoff time of 15 seconds was maintained.

\section{Biochemical Analysis}

Blood samples were collected by retro-orbital sinus puncture under anesthesia (diethyl ether) at different time intervals (i.e., days 4 and 25). Serum samples were prepared for the estimation of uremic marker (i.e., creatinine level) changes in rats. Furthermore, the sciatic nerve was removed on day 25 and homogenized for biochemical analysis of total calcium, superoxide anion, DNA, and transketolase and myeloperoxidase activity.

\section{Assessment of renal function}

Creatinine was estimated in serum samples by use of spectrophotometric instruments (Spectrochem Instruments Pvt. Ltd., Hyderabad, India) with standard diagnostic kits (Span Diagnostics, Gujarat, India). Abnormal changes in the creatinine level served as an indicator of impairement of glomerular function and the presence of uremia throughout the study protocol.

\section{Estimation of total calcium}

Total calcium levels were estimated in the sciatic nerve as described by Severnghaus and Ferrebee [20] and Muthuraman et al. [21]. Briefly, the sciatic nerve homogenate was mixed with 1 $\mathrm{mL}$ of trichloroacetic acid (4\%) in the ice-cold condition and centrifuged at $1,500 \times \mathrm{g}$ for 10 minutes. The clear supernatant was used for estimating the total calcium levels atomic emission spectroscopy at $\mathrm{A}^{556} \mathrm{~nm}$.

\section{Estimation of superoxide anion}

The sciatic nerve superoxide anion generation was estimated in terms of measuring reduced NBT as described in the method of Wang et al. [22]. The absorbance of formazan was determined by spectrophotometrically at $\mathrm{A}^{540} \mathrm{~nm}$.

The quantity of NBT reduction $=\mathrm{A} \times \mathrm{V} /(\mathrm{T} \times \mathrm{Wt} \times \varepsilon \times \mathrm{l})$,

Where $\mathrm{A}$ is the absorbance of blue formazan at $540 \mathrm{~nm}, \mathrm{~V}$ is the volume of the solution, $\mathrm{T}$ is the time period (90 minutes) during which rings were incubated with NBT, Wt is the blotted wet weight of the sciatic nerve, $\varepsilon$ is the extinction coefficient of blue formazan (i.e., $0.72 \mathrm{~L} / \mathrm{mM} / \mathrm{mm}$ ), and $1 \mathrm{~cm}$ is the length of the light path. Results are reported as picomoles per minute per milligram of protein. 


\section{Estimation of DNA}

Nucleic acid extraction was performed as described by Schneider [23]. Sciatic nerve DNA was estimated in terms of DNA fragmentation as described in the methods of Dische [24] and Stumpf [25]. Briefly, the method depends on the production of a pink color by the reaction of cysteine and sulfuric acid with DNA as an index of DNA fragmentation. Absorbance was determined spectrophotometrically at $\mathrm{A}^{490} \mathrm{~nm}$.

\section{Estimation of transketolase activity}

Transketolase (EC 2.2.1.1) is a ubiquitous thiamine diphosphate (ThDP)-dependent enzyme that plays an important role in the oxidative pentose phosphate pathway of virtually all organisms. Transketolase activity was assessed in terms of R5P consumption as described by Dische and Borenfreund [26]. Absorbance was determined spectrophotometrically at $\mathrm{A}^{510}$ and $\mathrm{A}^{552} \mathrm{~nm}$ and subtracted.

\section{Estimation of myeloperoxidase activity}

Myeloperoxidase, an enzyme liberated due to the activation of polymorphonuclear leukocytes, is used as an indication of tissue neutrophil accumulation. Myeloperoxidase activity was measured by using a procedure similar to that documented by Hillegass et al. [27]. The absorbance was determined spectrophotometrically at $\mathrm{A}^{460} \mathrm{~nm}$ for 3 minutes. Myeloperoxidase ac- tivity was expressed as unit per gram tissue. One unit of myeloperoxidase activity was defined as that degrading $1 \mu \mathrm{M}$ peroxide per minute at $25^{\circ} \mathrm{C}$.

\section{Estimation of total protein content}

The protein concentration was estimated according to the method of Lowry et al. [28] by using bovine serum albumin as a standard. Absorbance was determined spectrophotometrically at $\mathrm{A}^{750} \mathrm{~nm}$.

\section{Statistical Analysis}

All results were expressed as means \pm standard deviations (SDs). The data for all biochemical variables were statistically analyzed by one-way analysis of variance followed by Tukey's multiple range tests by using Sigmastat Version-2.0 software. $\mathrm{P}<0.05$ were considered to be statistically significant.

\section{RESULTS}

\section{Effect of Flunarizine on Changes in Renal Functional Markers}

Cisplatin administration resulted in a significant rise in the levels of creatinine on days 4 and 25 compared with the vehicle control group (Fig. 1). Administration of flunarizine (100, 200, and $300 \mu \mathrm{M} / \mathrm{kg}$ ) attenuated the cisplatin-induced changes in

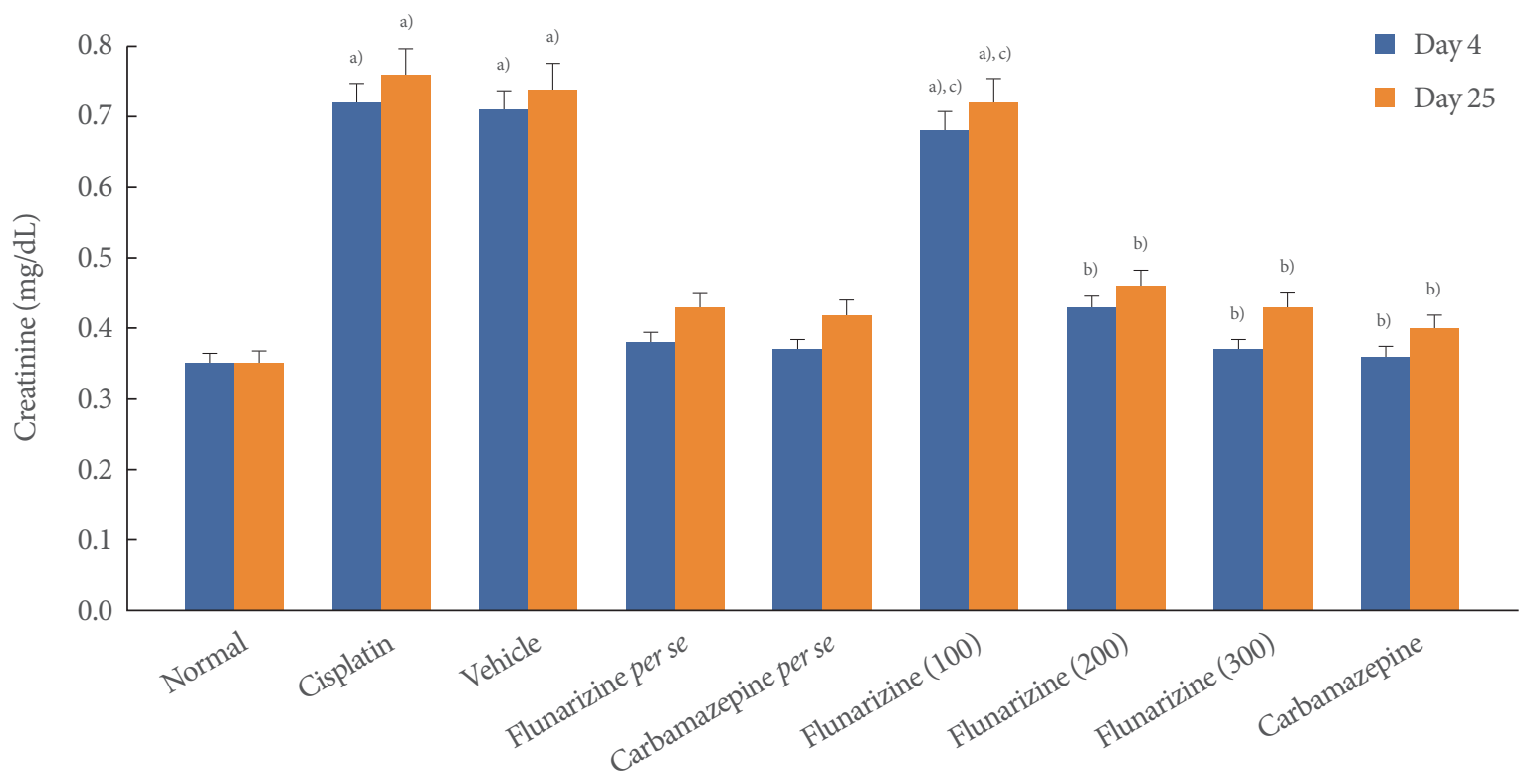

Fig. 1. Effect of flunarizine on serum creatinine levels on day 4 and day 25. Data in parentheses indicate the dose of flunarizine in $\mu \mathrm{M} /$ $\mathrm{kg}$. Values are the mean \pm SD of 6 animals. Statistical values for serum creatinine level $\mathrm{F}(8,53)=5743.16, \mathrm{P}<0.001 .{ }^{\mathrm{a}} \mathrm{P}<0.05$ vs. sham control group. ${ }^{\text {b) }} \mathrm{P}<0.05$ vs cisplatin control group. ${ }^{\text {c) }} \mathrm{P}<0.05$ vs. carbamazepine treated group. 
creatinine levels in a dose-dependent manner. A significant $(\mathrm{P}<0.05)$ effect was observed in the groups treated with the medium and high doses. Treatment with carbamazepine produced similar effects. Moreover, the flunarizine and carbamazepine per se treated groups did not show any significant biochemical changes.

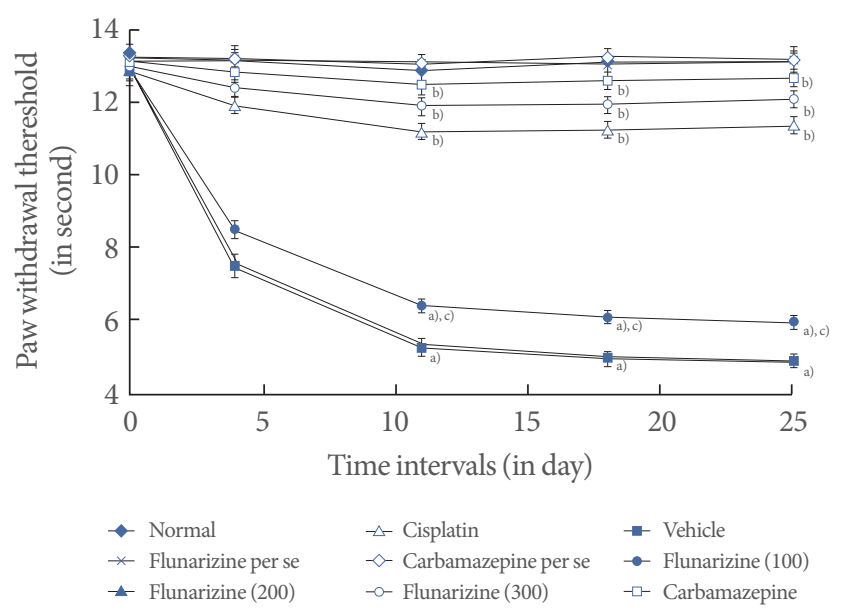

Fig. 2. Effect of flunarizine on the hot plate test. Data in parentheses indicate the dose of flunarizine in $\mu \mathrm{M} / \mathrm{kg}$. Values are the mean \pm SD of 6 animals. Statistical values for hot plate test $F$ (8, 53) $=186,047 ; \mathrm{P}<0.001 .{ }^{\text {a) }} \mathrm{P}<0.05$ vs. sham control group. ${ }^{\text {b) }} \mathrm{P}$ $<0.05$ vs. cisplatin control group. ${ }^{\text {c) }} \mathrm{P}<0.05$ vs. carbamazepine treated group.

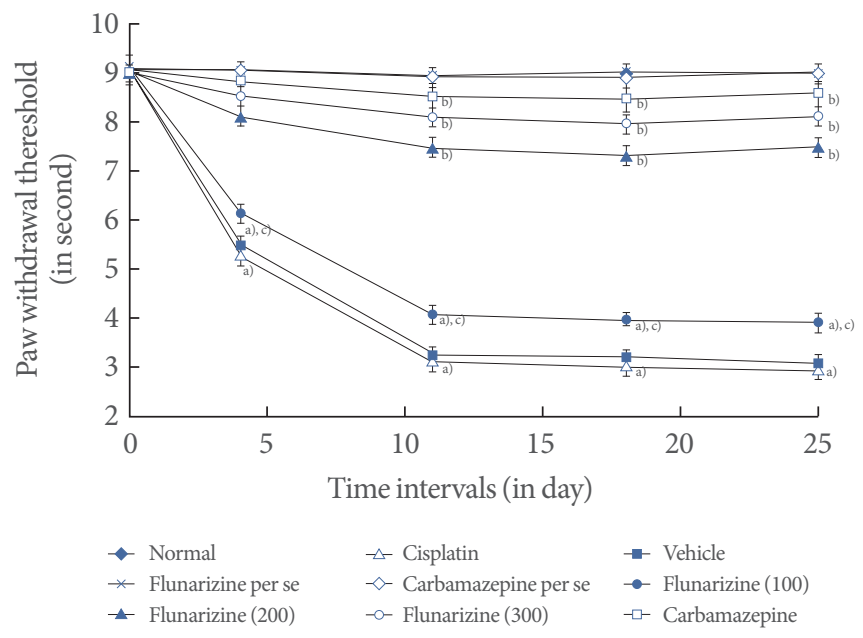

Fig. 4. Effect of flunarizine on the tail immersion test. Data in parentheses indicate the dose of flunarizine in $\mu \mathrm{M} / \mathrm{kg}$. Values are the mean \pm SD of 6 animals. Statistical values for tail immersion test $\mathrm{F}(8,53)=125.083 ; \mathrm{P}<0.001$. $^{\mathrm{a})} \mathrm{P}<0.05$ vs. sham control group. ${ }^{\text {b) }} \mathrm{P}<0.05$ vs. cisplatin control group. ${ }^{\text {c) }} \mathrm{P}<0.05$ vs. carbamazepine treated group.

\section{Effect of Flunarizine on Behavioral Changes}

Cisplatin administration resulted in a significant development of thermal hyperalgesia as reflected by decreased paw and tail withdrawal latency in the hot plate, plantar, tail immersion, and tail flick tests compared with the vehicle control group (Figs. $2-5)$. Administration of flunarizine $(100,200$, and $300 \mu \mathrm{M} / \mathrm{kg})$

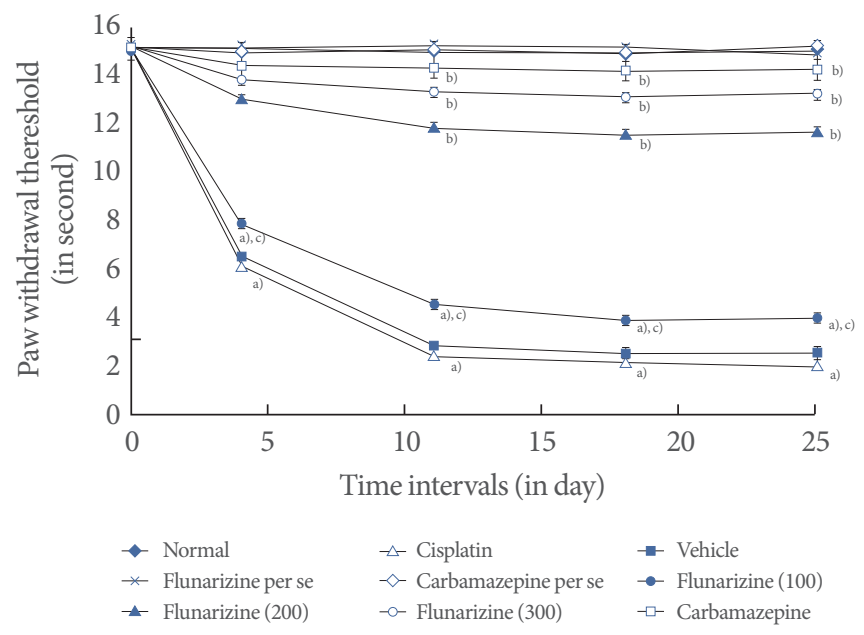

Fig. 3. Effect of flunarizine on the plantar test. Data in parentheses indicate the dose of flunarizine in $\mu \mathrm{M} / \mathrm{kg}$. Values are the mean \pm SD of 6 animals. Statistical values for plantar test F (8, $53)=173.103$; $\mathrm{P}<0.001$. ${ }^{\text {a) }} \mathrm{P}<0.05$ vs. sham control group. ${ }^{\text {b) }} \mathrm{P}$ $<0.05$ vs. cisplatin control group. ${ }^{\text {c) }} \mathrm{P}<0.05$ vs. carbamazepine treated group.

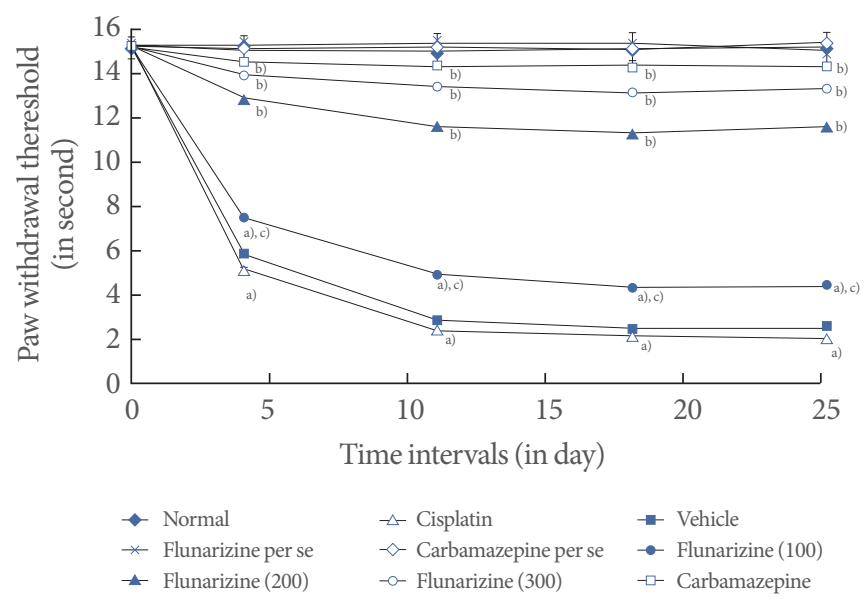

Fig. 5. Effect of flunarizine on the tail flick test. Data in parentheses indicate the dose of flunarizine in $\mu \mathrm{M} / \mathrm{kg}$. Values are the mean \pm SD of 6 animals. Statistical values for tail flick test $F$ (8, $53)=216.037 ; \mathrm{P}<0.001 .{ }^{a)} \mathrm{P}<0.05$ vs. sham control group. ${ }^{\text {b) }} \mathrm{P}$ $<0.05$ vs. cisplatin control group. ${ }^{\text {c) }} \mathrm{P}<0.05$ vs. carbamazepine treated group. 
Table 1. Effect of flunarizine on tissue biomarker changes

\begin{tabular}{lccccc}
\hline Group & $\begin{array}{c}\text { Total calcium } \\
(\mathrm{ppm} / \mathrm{mg} \text { of protein })\end{array}$ & $\begin{array}{c}\text { Superoxide anion } \\
(\mathrm{pM} / \mathrm{mg} \text { of protein })\end{array}$ & $\begin{array}{c}\text { DNA } \\
(\mu \mathrm{g} / \mathrm{mg} \text { of protein })\end{array}$ & $\begin{array}{c}\text { Transketolase activity } \\
(\mathrm{nM} / \mathrm{min} / \mathrm{mg} \text { of protein })\end{array}$ & $\begin{array}{c}\text { Myeloperoxidase activity } \\
(\mathrm{U} / \mathrm{min} / \mathrm{mg} \text { of protein })\end{array}$ \\
\hline I & $3.64 \pm 1.06$ & $3.54 \pm 0.98$ & $41.31 \pm 1.36$ & $156.18 \pm 4.62$ & $11.64 \pm 1.51$ \\
II & $34.81 \pm 1.26^{\mathrm{a})}$ & $22.37 \pm 1.23^{\mathrm{a})}$ & $85.12 \pm 1.04^{\mathrm{a})}$ & $89.46 \pm 2.71^{\mathrm{a})}$ & $164.24 \pm 3.89^{\mathrm{a})}$ \\
III & $35.27 \pm 0.94^{\mathrm{a})}$ & $21.64 \pm 1.41^{\mathrm{a})}$ & $83.83 \pm 0.94^{\mathrm{a})}$ & $87.19 \pm 1.94^{\mathrm{a})}$ & $161.63 \pm 4.01^{\mathrm{a})}$ \\
IV & $3.52 \pm 0.89$ & $3.72 \pm 1.03$ & $40.09 \pm 1.13$ & $157.32 \pm 3.39$ & $11.94 \pm 1.09$ \\
V & $3.59 \pm 1.32$ & $3.61 \pm 0.99$ & $42.15 \pm 1.09$ & $159.54 \pm 4.91$ & $12.08 \pm 0.92$ \\
VI & $29.83 \pm 1.08^{\mathrm{a}, \mathrm{c})}$ & $17.83 \pm 1.24^{\mathrm{a}, \mathrm{c})}$ & $76.05 \pm 1.64^{\mathrm{a}), \mathrm{c})}$ & $96.37 \pm 2.56^{\mathrm{a}), \mathrm{c}}$ & $139.63 \pm 3.53^{\mathrm{a})}$ \\
VII & $10.17 \pm 1.13^{\mathrm{b})}$ & $8.32 \pm 0.96^{\mathrm{b})}$ & $48.41 \pm 0.96^{\mathrm{b})}$ & $139.88 \pm 2.95^{\mathrm{b})}$ & $53.73 \pm 3.92^{\mathrm{b})}$ \\
VIII & $7.94 \pm 1.52^{\mathrm{b})}$ & $4.82 \pm 1.35^{\mathrm{b})}$ & $42.18 \pm 1.31^{\mathrm{b})}$ & $147.73 \pm 3.43^{\mathrm{b})}$ & $38.65 \pm 3.36^{\mathrm{b})}$ \\
IX & $4.18 \pm 0.86^{\mathrm{b})}$ & $3.42 \pm 1.04^{\mathrm{b})}$ & $39.71 \pm 1.06^{\mathrm{b})}$ & $151.37 \pm 3.71^{\mathrm{b})}$ & $24.62 \pm 1.14^{\mathrm{b})}$ \\
\hline
\end{tabular}

Values are presented as mean \pm SD of 6 animals.

Statistical values for total calcium $\mathrm{F}(8,53)=436524.7, \mathrm{P}<0.001$; for superoxide anion $\mathrm{F}(8,53)=3517.4, \mathrm{P}<0.001$; deoxyribonucleic acid (DNA) $\mathrm{F}$ (8, $53)=29463.1, \mathrm{P}<0.001$; for transketolase activity $\mathrm{F}(8,53)=156839.08, \mathrm{P}<0.001$, and for myeloperoxidase activity $\mathrm{F}(8,53)=3684.2, \mathrm{P}<0.001$.

${ }^{\text {a) }} \mathrm{P}<0.05$ vs. sham control group. ${ }^{\text {b) }} \mathrm{P}<0.05$ vs. cisplatin control group. ${ }^{\text {c) }} \mathrm{P}<0.05$ vs. carbamazepine treated group.

attenuated the cisplatin-induced behavioral changes in a dosedependent manner. A significant $(\mathrm{P}<0.05)$ effect was observed in the groups treated with the medium and high doses. Treatment with carbamazepine produced similar effects. Moreover, the flunarizine and carbamazepine per se treated groups did not show any significant behavioral changes.

\section{Effect of Flunarizine on Tissue Biochemical Changes}

Cisplatin administration resulted in a significant rise in the level of tissue total calcium, superoxide anion, deoxyribonucleic acid, transketolase, and myeloperoxidase activity compared with the vehicle control group (Table 1). Administration of flunarizine $(100,200$, and $300 \mu \mathrm{M} / \mathrm{kg})$ attenuated the cisplatin-induced tissue biochemical changes in a dose-dependent manner. A significant $(\mathrm{P}<0.05)$ effect was observed in the groups treated with medium and high doses. Treatment with carbamazepine produced similar effects. Moreover, the flunarizine and carbamazepine per se treated groups did not show any significant effect on tissue biochemical changes.

\section{DISCUSSION}

In the present study, cisplatin $(2 \mathrm{mg} / \mathrm{kg}$; i.p. for 5 consecutive days) administration produced the development of uremia (i.e., rise in level of creatinine), decreases in paw and tail withdrawal latency (central-peripheral thermal hyperalgesia), and tissue biochemical changes, such as in total calcium, superoxide anion, DNA, and transketolase and myeloperoxidase, activity in rats. Flunarizine and carbamazepine attenuated the cisplatininduced behavioral and biochemical alterations. Previous studies revealed that cisplatin can cause nephro-, neuro-, hepato-, cardio-, and ototoxicity in humans and animals [4,29]. Cisplatin has also been reported to induce the uremic condition in experimental research [15]. Various uremic toxins play a major role in the pathogenesis of disease including neuropathic pain $[1,6]$.

The most important hypothesis of our study explains that cisplatin-induced neurotoxicity is caused by enhancement of uremic toxin accumulation which leads to free radical generation, calcium overload, DNA breakdown, and alteration of transketolase and myeloperoxidase activity associated with increased peripheral as well as central neuropathic pain sensation i.e., paw and tail withdrawal latency against conduction and radiant heat stimuli in rat. These changes have also been observed in various types of neuropathic pain [30] including in our earlier findings [21,31-33]. The production of oxidative stress by the generation of free radicals (reactive oxygen and reactive nitrogen species) along with calcium accumulation plays a major role in the pathogenesis of neuropathy as well as in other diseases [32,33]. Cisplatin has been reported to induce oxidative stress via free radical generation, lipid peroxidation, and calcium accumulation in the uremic condition [10]. Clinical and preclinical reports of cisplatin treatment have shown that the production of oxidative stress, enzymatic changes and DNA breakdown leads to inflammation of the renal and nervous system under in the uremic condition $[34,35]$. 
In the present study, cisplatin administration appeared to induce behavioral changes as well as biochemical changes. Moreover, these results were obtained under the uremic condition in rats, i.e., according to the index of creatinine levels in blood samples. However, flunarizine (T-type calcium channel antagonist) treatment was shown to reduce such neuropathic pain development along with amelioration of the biochemical changes. Our earlier findings also suggested that flunarizine has a potential role in the regulation of cellular calcium, free radical generation, and alteration of the uremic condition via the modulation of membrane permeability transition pore activation in rats [10]. Flunarizine is known to possess free radical scavenging activity via closing of calcium channels [36]. Calcium-induced activation of calpain (calcium binding protein) and generation of free radicals from mitochondria play a major role in the development of neuropathic pain and axonal degeneration [21,31-33]. In the present study, flunarizine was found to have ameliorative effect on cisplatin induced painful uremic neuropathy in rats which was comparable to that of carbamazepine. Therefore, it may serve as potential therapeutic agent for the management of uremic neuropathy due to its potential anti-oxidant, anti-inflammatory, neuro and nephroprotective actions. However, the elaborative studies are required to explore the molecular mechanism, in the management of uremic neuropathy.

\section{CONFLICT OF INTEREST}

No potential conflict of interest relevant to this article was reported.

\section{ACKNOWLEDGEMENTS}

Thanks to all faculty members of Rayat Institute of Pharmacy for their encouragement and support. We are also grateful to Rayat \& Bahra Educational and Research Trust for their unconditional help in carrying out this project.

\section{REFERENCES}

1. Krishnan AV, Kiernan MC. Uremic neuropathy: clinical features and new pathophysiological insights. Muscle Nerve 2007;35:273-90.

2. Fong CS. Neurological complications in uremia. Acta Neurol Taiwan 2008;17:117-26.

3. Rodrigues MA, Rodrigues JL, Martins NM, Barbosa F, Curti C,
Santos NA, et al. Carvedilol protects against the renal mitochondrial toxicity induced by cisplatin in rats. Mitochondrion 2010;10: 46-53.

4. Hill A, Bergin P, Hanning F, Thompson P, Findlay M, Damianovich $\mathrm{D}$, et al. Detecting acute neurotoxicity during platinum chemotherapy by neurophysiological assessment of motor nerve hyperexcitability. BMC Cancer 2010;10:451.

5. Silici S, Ekmekcioglu O, Kanbur M, Deniz K. The protective effect of royal jelly against cisplatin-induced renal oxidative stress in rats. World J Urol 2011;29:127-32.

6. Iwata K, Watanabe H, Morisaki T, Matsuzaki T, Ohmura T, Hamada $\mathrm{A}$, et al. Involvement of indoxyl sulfate in renal and central nervous system toxicities during cisplatin-induced acute renal failure. Pharm Res 2007;24:662-71.

7. Zakrzewska-Pniewska B, Jedras M. Is pruritus in chronic uremic patients related to peripheral somatic and autonomic neuropathy? Study by R-R interval variation test (RRIV) and by sympathetic skin response (SSR). Neurophysiol Clin 2001;31:181-93.

8. Murai K, Tyler RS, Harker LA, Stouffer JL. Review of pharmacologic treatment of tinnitus. Am J Otol 1992;13:454-64.

9. Konrad T, Bloechle C, Haller G, Broelsch CE, Usadel KH, Kusterer K. Verapamil and flunarizine protect the isolated perfused rat liver against warm ischemia and reperfusion injury. Res Exp Med (Berl) 1995;195:61-8.

10. Muthuraman A, Sood S, Singla SK, Rana A, Singh A, Singh A, et al. Ameliorative effect of flunarizine in cisplatin-induced acute renal failure via mitochondrial permeability transition pore inactivation in rats. Naunyn Schmiedebergs Arch Pharmacol 2011;383:5764.

11. So HS, Park C, Kim HJ, Lee JH, Park SY, Lee JH, et al. Protective effect of T-type calcium channel blocker flunarizine on cisplatininduced death of auditory cells. Hear Res 2005;204:127-39.

12. Zakrzewska JM, Linskey ME. Trigeminal neuralgia. Clin Evid (Online) 2009;2009:1207.

13. Waszkielewicz AM, Gunia A, Słoczyńska K, Marona H. Evaluation of Anticonvulsants for Possible Use in Neuropathic Pain. Curr Med Chem 2011 Aug 24 [Epub].

14. Ling B, Authier N, Balayssac D, Eschalier A, Coudore F. Behavioral and pharmacological description of oxaliplatin-induced painful neuropathy in rat. Pain 2007;128:225-34.

15. Morisaki T, Matsuzaki T, Yokoo K, Kusumoto M, Iwata K, Hamada A, et al. Regulation of renal organic ion transporters in cisplatininduced acute kidney injury and uremia in rats. Pharm Res 2008; 25:2526-33.

16. Borta A, Schwarting RK. Inhibitory avoidance, pain reactivity, and 
plus-maze behavior in Wistar rats with high versus low rearing activity. Physiol Behav 2005;84:387-96.

17. Hargreaves K, Dubner R, Brown F, Flores C, Joris J. A new and sensitive method for measuring thermal nociception in cutaneous hyperalgesia. Pain 1988;32:77-88.

18. Necker R, Hellon RF. Noxious thermal input from the rat tail: modulation by descending inhibitory influences. Pain 1978;4:23142.

19. D’Amour FE, Smith DL. A method for determining loss of pain sensation. J Pharmacol Exp Ther 1941;72:74-9.

20. Severinghaus JW, Ferrebee JW. Calcium determination by flame photometry; methods for serum, urine, and other fluids. J Biol Chem 1950;187:621-30.

21. Muthuraman A, Diwan V, Jaggi AS, Singh N, Singh D. Ameliorative effects of Ocimum sanctum in sciatic nerve transection-induced neuropathy in rats. J Ethnopharmacol 2008;120:56-62.

22. Wang HD, Pagano PJ, Du Y, Cayatte AJ, Quinn MT, Brecher P, et al. Superoxide anion from the adventitia of the rat thoracic aorta inactivates nitric oxide. Circ Res 1998;82:810-8.

23. Schneider WC. Phosphorus compounds in animal tissues; extraction and estimation of desoxypentose nucleic acid and of pentose nucleic acid. J Biol Chem 1945;161:293-303.

24. Dische Z. Two characteristic and sensitive color reactions between sulfhydryl compounds and thymonucleic acid. Proc Soc Exp Biol Med 1944;55:217-8.

25. Stumpf PK. A colorimetric method for the determination of desoxyribonucleic acid. J Biol Chem 1947;169:367-71.

26. Dische Z, Borenfreund E. A new color reaction for the determination of aldopentose in presence of other saccharides. Biochim Biophys Acta 1957;23:639-42.
27. Hillegass LM, Griswold DE, Brickson B, Albrightson-Winslow C. Assessment of myeloperoxidase activity in whole rat kidney. J Pharmacol Methods 1990;24:285-95.

28. Lowry OH, Rosebrough NJ, Farr AL, Randall RJ. Protein measurement with the Folin phenol reagent. J Biol Chem 1951;193:265-75.

29. Wang J, He D, Zhang Q, Han Y, Jin S, Qi F. Resveratrol protects against Cisplatin-induced cardiotoxicity by alleviating oxidative damage. Cancer Biother Radiopharm 2009;24:675-80.

30. Barabas K, Milner R, Lurie D, Adin C. Cisplatin: a review of toxicities and therapeutic applications. Vet Comp Oncol 2008;6:1-18.

31. Muthuraman A, Jaggi AS, Singh N, Singh D. Ameliorative effects of amiloride and pralidoxime in chronic constriction injury and vincristine induced painful neuropathy in rats. Eur J Pharmacol 2008;587:104-11.

32. Muthuraman A, Ramesh M, Sood S. Development of animal model for vasculatic neuropathy: Induction by ischemic-reperfusion in the rat femoral artery. J Neurosci Methods 2010;186:215-21.

33. Muthuraman A, Sood S. Pharmacological evaluation of tacrolimus (FK-506) on ischemia reperfusion induced vasculatic neuropathic pain in rats. J Brachial Plex Peripher Nerve Inj 2010;5:13.

34. Hauser AB, Azevedo IR, Gonçalves S, Stinghen A, Aita C, PecoitsFilho R. Sevelamer carbonate reduces inflammation and endotoxemia in an animal model of uremia. Blood Purif 2010;30:153-8.

35. Manenti L, Tansinda P, Vaglio A. Uraemic pruritus: clinical characteristics, pathophysiology and treatment. Drugs 2009;69:251-63.

36. Takei M, Hiramatsu M, Mori A. Inhibitory effects of calcium antagonists on mitochondrial swelling induced by lipid peroxidation or arachidonic acid in the rat brain in vitro. Neurochem Res 1994; 19:1199-206 